\title{
Perspectives of Service Agencies on Factors Influencing Immigrants' Mental Health in Alberta, Canada
}

\author{
Original Research \\ Dominic A. Alaazi ${ }^{1}$, Salima Meherali ${ }^{2}$, Esperanza Diaz ${ }^{3}$, Kathleen Hegadoren ${ }^{2}$, Neelam Punjani ${ }^{2}$, Bukola Salami $^{2}$ \\ ${ }^{1}$ School of Public Health, University of Alberta, Edmonton, Alberta, Canada; ${ }^{2}$ Faculty of Nursing, University of Alberta, \\ Edmonton, Alberta, Canada; ${ }^{3}$ Department of Global Public Health and Primary Care, University of Bergen, Bergen, \\ Norway
}

Corresponding author: D.A. Alaazi (alaazi@ualberta.ca)

\begin{abstract}
Newcomers to Canada experience resettlement challenges that affect their mental well-being. Guided by an intersectionality theoretical framework, we explored the perspectives of immigrant service agencies on factors influencing immigrants' mental health in Alberta, Canada. Data were collected by means of qualitative interviews and focus groups with immigrant service providers. Our data analysis identified seven themes - precarious immigration status, employment discrimination, social isolation, socioeconomic pressures, sociocultural stress, gender and age-related vulnerabilities, and lack of appropriate mental health supports - reflecting the major intersecting determinants of immigrants' mental health. We propose policy interventions for addressing the mental health vulnerabilities of immigrants.
\end{abstract}

KEYWORDS

Immigrants; Intersectionality Theory; Mental Health; Resettlement Challenges; Well-Being

FUNDING SOURCE

This work received funding from Policywise for Children and Families (Grant \#: 15SM).

\section{BACKGROUND}

Cross-border migration of people has increased globally over the last three decades. In 2020, an estimated 281 million people lived outside their country of origin, 60 million of whom emigrated in the last 10 years (UN Department of Economic and Social Affairs, 2020). Although most cross-border migrants are found in the global south, a significant proportion has settled in developed countries, including the United States, United Kingdom, Australia, and Canada. Data from Canada's 2016 Population Census indicate that the country was home to over 7.5 million immigrants, constituting approximately $22 \%$ of the country's total population (Statistics Canada, 2018). An estimated 207,790 immigrants resided in Alberta in 2016 (Statistics Canada, 2016). Alberta's strong economy, thriving ethnoracial communities, and strong public service sectors have continued to promote the province as a favorable immigrant destination in Canada. Provincial policies, including the Alberta Immigrant Nominee Program (AINP), have also been deliberately redesigned to attract immigrants as a stopgap remedy for labour shortages in the province. As these immigrants become a vital part of Albertan society, it is important to understand their settlement experiences.

Research across the globe has suggested
newcomers face considerable resettlement
challenges in destination countries, some of which
can have detrimental impacts on their physical and
mental well-being. Immigrants usually arrive in
destination countries with high hopes and

IHTP, 1(2), 214-225, 2021 CC BY-NC-ND 4.0 
expectations. However, they can feel frustrated, disappointed, and depressed when their initial hopes and expectations are not realized (Chadwick \& Collins, 2015; Menezes, Georgiades, \& Boyle, 2011; Shishehgar, Gholizadeh, DiGiacomo, \& Davidson, 2015; Srirangson, Thavorn, Moon, \& Noh, 2013; Stafford, Newbold, \& Ross, 2011). The discrepancy between pre-emigration expectations and the realities of resettlement can have serious health implications.

Compared to their native-born counterparts, newcomers to the United States, United Kingdom, Australia, and Canada usually arrive with better health status, a phenomenon known as the 'healthy immigrant effect' (Islam, 2013; Kennedy, Kidd, McDonald, \& Biddle, 2015; Ng \& Omariba, 2010; Rechel, Mladovsky, Ingleby, Mackenbach, \& McKee, 2013; Robert \& Gilkinson, 2012; Vang, Sigouin, Flenon, \& Gagnon, 2015). Several immigration policies and practices, including rigorous medical screening and deliberate selection of healthier, younger, and more educated applicants, give rise to the healthy immigrant effect (Kennedy et al., 2015; $\mathrm{Ng}, 2011$; Vang et al., 2015). Canada and Australia, for example, attract young, educated, and skilled immigrants through a points-based system that explicitly considers age, educational attainment, and language proficiency as entry requirements. Similarly, the United States offers temporary work visas to highly educated and skilled individuals with superior health attributes (Kennedy et al., 2015). However, despite these initial health advantages, the physical and mental health of immigrants tends to deteriorate and even decline to native-born levels after some time in destination countries (Islam, 2013; Kirmayer et al., 2011; Ng \& Omariba, 2010; Straiton, Grant, Winefield, \& Taylor, 2014). Research on health transition among Canadian immigrants suggests that recent immigrants have fewer depressive symptoms and lower rates of depression and alcohol dependence than those who have been in Canada for a decade or more (Ali, 2002; Islam, 2013).

Research on the mental health and general wellbeing of newcomers is limited in several of the major immigrant-destination countries. The few available studies on immigrants' mental health relied on quantitative analysis of a limited number of measurable variables (Islam \& Oremus, 2014; Nangia, 2013; Ng \& Omariba, 2010; Rivera, Casal, \& Currais, 2016; Robert \& Gilkinson, 2012; Statistics Canada,
2013), which does not sufficiently account for the contextual factors influencing the mental health of this demographic. The rapid increase in immigrant populations in destination countries makes a strong case for qualitative insights that can help inform mental health supports for immigrants.

In the Canadian province of Alberta, a wide gap in mainstream mental health services exists for newcomers (Salami, Salma, \& Hegadoren, 2019). Community service agencies are currently involved in bridging the gap in mental health services and supports for immigrant in the province. However, research in the province has yet to explore the perspectives of these service providers regarding the determinants of immigrant mental health. This study was therefore designed to explore service providers' understanding of the factors influencing immigrant mental health in this Canadian province. We sought specifically to address the question, "What factors do immigrant service agencies perceive as the key determinants of the mental health of immigrants in Alberta?"

\section{THEORETICAL FRAMEWORK}

An intersectionality theoretical perspective guided the conceptualization and conduct of this research (Crenshaw, 1989). Intersectionality theory addresses the predisposition of certain population groups to multiple and often concurrent social and economic disadvantages based on race, gender, and class (Collins, 2000). In the context of immigration, the theory highlights how the interaction of race, gender, and social class can create socioeconomic and health disadvantages for immigrant groups. Viruell-Fuentes, Miranda, and Abdulrahim (2012) suggest intersectionality theory as an alternative analytical framework that shifts explanations of health inequities from individual-level factors to structurallevel examinations of the role of power, race, class, gender, and immigration status.

Although the primary focus of Crenshaw's original work was to explain the social disadvantages of Black women in the United States, intersectionality theory has since evolved into a potent analytical lens through which the health vulnerabilities of marginalized groups can be understood. In this research, we adopted an intersectionality theoretical gaze to reflect the similarities in social position between American Black women and Canadian immigrants. 
First, similar to American Black women, the majority of immigrants in Alberta and across Canada are peoples of colour, whose experiences have been shaped by their racial identities (Statistics Canada, 2013). Second, the minority status of Canadian immigrants places them at socioeconomic disadvantages in a manner similar to those experienced by the Black women who formed the subjects of Crenshaw's theorization in the 1980s. In these regards, intersectionality theory offers an analytical lens for identifying the structural determinants of the mental health of immigrants in the Canadian context.

\section{METHODS}

\section{Participants and data collection}

Our research design relied on a qualitative descriptive methodology involving interviews and focus groups (Sandelowski, 2000). After obtaining ethics approval from the University of Alberta Research Ethics Board, we invited individuals from immigrant service agencies to participate in the study. We identified potential participants by contacting known immigrant service agencies across the province. Our targeted participants were frontline workers who worked directly with different categories of immigrants, including refugees, economic immigrants, and temporary foreign workers, to address their social and mental health challenges in the province. Their direct and regular contact with immigrant populations meant that these individuals were knowledgeable enough to speak to the factors affecting immigrants' mental health.

At the initial contact, we gave potential participants the option of participating in an individual interview or a focus group. Overall, we conducted 6 face-to-face individual interviews and six focus groups (of 47 participants) over the period September to December 2016. The 53 participants represented nine different immigrant service agencies across Alberta, and included both mental health practitioners and social service providers. There was no data redundancy because some of the participants, despite working at the same agency, had different professional expertise and played very different roles in supporting the mental health of immigrants. For instance, in one agency, we recruited three participants who were each specialized in provision of mental health supports to different categories of immigrants: temporary foreign workers, economic migrants, and refugees. These immigrant groups had different mental health needs that required supports from professionals with different expertise. Given their role in the study as key informants rather than immigrants with lived experiences of immigration, we made a decision to restrict collection of participant demographics to only age, gender, and country of origin.

All interviews and focus groups were semistructured, audio-recorded, and completed by a member of the research team. Participants were, for example, asked, "What are the key mental health concerns of your clients?"; "What factors underlie these concerns", etc. On average, the individual interviews lasted approximately 45 minutes (ranging from 30 to 60 minutes), while the focus groups lasted approximately 2 hours. For their convenience, all interviews and focus groups occurred in the participants' office premises. Each participant read the informed consent documents and consented to participate.

\section{Data analysis}

All interviews and focus groups were transcribed verbatim and analyzed thematically using NVivo 11, a qualitative data management software. Intersectionality theory guided the process of data coding, interpretation, and identification of themes, wherein we paid attention to how race, gender, culture, and social status intersect to create mental health vulnerabilities among immigrants. The data coding process was inductive, and followed Braun and Clark's (2006) thematic analytic process of reading, rereading, and sorting data into themes. In this regard, two members of the research team independently read the interview transcripts to establish familiarity with the data. The two subsequently met to discuss the data, following which a codebook of preliminary nodes was developed. Disagreements between the two readers were resolved by consensus. In the final step, one member of the team coded the transcripts using NVivo 11, the data management functions of which supports data sorting into nodes and subsequently into themes.

We exercised reflexivity throughout the entire process of data collection and analysis (Lincoln \& Guba, 1985; Weis \& Fine, 2000), by: (a) maintaining a reflexive log book in which we recorded our emerging 
understanding of the data; and (b) reflecting on and documenting how our own social location as researchers, immigrants, and racial minorities influenced our understanding of the research context and emerging themes. We attained analytical $u$ by sharing the preliminary findings with the participants. Their feedback strengthened the analytic process and the accuracy of our findings.

\section{RESULTS}

The participants were themselves predominantly immigrant ( $n=49$ ) and female ( $n=47)$. All participants were more than 18 years in age. Our thematic analysis of the data resulted in the identification of several intersecting determinants of immigrants' mental health and well-being in Alberta. We categorized these factors into seven main themes, namely precarious immigration status, employment discrimination, social isolation, socioeconomic pressures, sociocultural stress, gender and age-related vulnerabilities, and lack of appropriate mental health supports.

\section{Precarious immigration status}

Although our participants suggested that most immigrants faced difficulties in settling and adjusting to life in Canada, they identified temporary foreign workers, refugee claimants, and undocumented migrants to be the most disadvantaged in the resettlement process. As such, individuals belonging to these immigrant categories were reported as being more likely than economic migrants to present at service agencies with mental health issues, including anxiety, emotional problems, and depression. Our participants attributed the mental health vulnerability of these migrants to their precarious immigration status. A participant explained this peculiar vulnerability:

For temporary workers, there is an added element of instability because of not knowing how long they are going to be here - [Individual interview 03].

Indeed, several of our participants reported encountering temporary foreign workers who were either anxious or psychologically stressed about their precarious immigration status, which included the expiration of work permits and uncertainties surrounding (non)renewal of resident permits. The resulting mental stress was observed to be even more intense for undocumented migrants who, in addition to lacking access to mainstream services (e.g. healthcare), lived in fear of deportation and possibly social and economic displacement in their country of origin. An interview participant explained the disconnection of undocumented migrants and their families from services:

Undocumented workers... they become undocumented and then they can't even access Alberta health care... if they have a work permit but then when they lose their work permit, so that's like in-between status, even though the children are Canadian citizen by birth, they don't get health care service. - [Individual interview 05].

Refugee claimants reportedly also lived in fear of losing their claim to refugee status, and as such experienced the anxiety associated with fear of deportation. According to participants, many of these claimants had come from countries where they experienced or witnessed war-related atrocities, including rape and extrajudicial killings. Our participants described the thought of deportation as one that traumatized refugee claimants. A participant explained:

Being a refugee claimant on its own is a very challenging process. So, having been persecuted, having been discriminated against back home, and coming here and not being able to even be successful in your claim adds on to the already fragile mental health. - [Individual interview 04].

In a nutshell, participants identified precarious immigration status as a major source of stress that added to the psychological and mental burden of temporary foreign workers and refugee claimants, some of whom reportedly had past experiences of posttraumatic stress disorders and depression caused by violence, religious persecutions, and poverty.

\section{Employment discrimination}

According to participants, a large number of immigrants in the province were either unemployed or working in menial part-time jobs that were not commensurate with their educational qualifications and previous work experiences. They noted that, despite having comparable and in some instances better educational and professional qualifications than non-immigrants, immigrants struggled to find 
suitable work. A large number of immigrants across the province were said to be working in low-skilled and low-wage jobs. They observed that even highly skilled immigrant professionals had difficulty finding suitable work, although it was the same credentials that qualified them for admission to Canada. The participants blamed racial discrimination, an overemphasis on Canadian work experience, and outright disregard for foreign-acquired qualifications for the inability of immigrants to find suitable employment. Consequently, a significant proportion of our participants' clients were reported to be individuals who also experienced poverty, material deprivation, and eventually psychosocial stress. One participant cited an example of a highly educated immigrant client who was distressed about having to accept work in a low-wage service industry:

There was an Indian couple. The husband was an engineer, and his wife was into government jobs, and she had two or three PhDs. . And when she came here she had to undergo all this stressful, you know, processes. And she was ... cry[ing], "I am going to have to go to Jugo Juice and say 'May I help you?" She got a job, ... an entry-level job, right? [Back home], she used to work at the government. . the elite type of white-collar job... She was just cry[ing], "What am I doing here and why am I here? I just want to go back.". .. She was so humiliated, so insulted, like, "What have I done to myself?" - [Focus group 1 participant].

Many participants stated that immigrants who had not fulfilled their dreams of improving their economic circumstances in Canada often suffered from depression, psychosomatic problems, marital conflicts, alcohol abuse, and suicide ideation. The relationship between minority status, employment discrimination, poverty, and psychosocial stress exemplifies how race and social class intersect to influence the mental health of immigrants in the province.

\section{Social isolation}

Although our participants considered community belonging, social capital, and informal support systems as critical mental health resources that can help cope with settlement challenges, they indicated that most of their immigrant clients lacked these resources. Instead, they experienced social isolation, loneliness, and disconnection from community.
According to participants, lack of community belonging and social supports often intersected with other resettlement stressors, such as unemployment, poverty, and poor language skills to create mental health stressors for immigrants. The participants therefore identified these intersecting factors as having detrimental impacts on the mental health of immigrants, including experiences of emotional problems and depression. A participant noted:

If a new immigrant who is coming here and does not have any family or friends, [they become isolated]. If they are connected to a community from their ethnicity and they feel a sense of belonging, they tend to [avoid] the isolation. .. the family and community structure is not available to them over here... So, I think that sense of belonging is really important, very important for their mental health. [Focus group 2 participant].

A focus group participant went further to identify social isolation and depression as a typical precursor for suicides and drug addiction among immigrant groups. She noted:

I have five to six people that, you know, committed suicide because nobody is there to help them...others just go for addiction of alcohol - [Focus group 1 participant].

\section{Socioeconomic pressures}

Per the participants' observation, the resettlement process required attaining a balance between family life and work, an adjustment reported to be physically and mentally stressful to immigrant women, especially those with no previous experience of labour force participation in their home countries. Participants revealed that the traditionally defined roles of some immigrant women were gender-specific and limited mostly to the domestic arena, while their husbands worked as income earners. However, upon arriving in Canada, the majority of these women are forced by economic pressures to work as income earners, thereby introducing additional and unanticipated responsibilities that added to the physical and mental stress of immigrant women. A focus group participant revealed the impact of socioeconomic pressures on immigrant women's mental health: 
So back home, in our countries, most of the women are not really working; [they] just take care of the house. But then there's a double responsibility over here, you have to work, and you have to create a balance with your children and in the house. So, all those pressures also kind of lead to mental illness and then it increases the stress. - [Focus group 6 participant].

In several instances, as noted by our participants, immigrant women were not only balancing family and a single job but family and multiple low-wage jobs, which substantially reduced their ability to perform their traditional roles as mothers, wives, and homemakers. The weight of the resulting stress, according to participants, was often compounded by the absence of extended family supports, particularly in the area of parenting.

\section{Sociocultural stress}

Our participants also identified sociocultural stress as a key determinant of the mental health of immigrants in Alberta. Upon settling in Canada, immigrants are typically exposed to value systems and norms of behaviour that deviate substantially from those held in their home countries. Accordingly, several of our participants observed that Western sociocultural influences have dramatically transformed power and gender relations in immigrant families, leading, in some instances, to conflicts, family destabilization, and mental health problems. A participant explained the cultural basis of parent-child conflicts in immigrant families:

I have heard clients say, "I don't know how to deal with my kids. . I don't know what's going on with my kids," and there has been a lot of conflicts. [There is an] imbalance that they are seeking help for. - [Individual interview 06].

According to several of our participants, immigrant parents generally believed that exposure to Western cultures and ways of living has severely affected their ability to train their children. In particular, enforcement of child rights in the Canadian context has been observed to curtail the ability of immigrant parents to discipline children. As such, children of immigrants were often said to make lifestyle choices that were inconsistent with parental expectations. This, our participants believed, has become a source of family conflict, with adverse mental health implications for both parents and children.

According to participants, sociocultural pressures have also exacerbated intimate-partner violence and led to increasing rates of divorce among immigrant families in the province. They suggested that the new social environment often produced irritants and tensions, some of which included changes in traditional gender relations, low socioeconomic status, unfulfilled dreams, and challenges with balancing work and family life. A participant identified intimate-partner violence as an outcome of these sociocultural stressors:

Many young women [are] exposed to or experience family violence from their husbands or partners, and it really causes mental health issues because, first of all, they are far away from their family, from their friends; there is no one to talk to or seek help from; they are not aware even of the services provided for women here in Canada. [Focus group 3 participant].

Participants also pointed to the growing number of single-parent households in the immigrant communities as a direct outcome of the multiple sociocultural stressors that they encountered upon resettlement. Thus, overall, immigrants in Alberta were reported as having difficulties in adjusting to their new sociocultural conditions, some of which can have adverse impacts on their mental health. Here, cultural incongruency, gender, and minority status (e.g., isolation) intersect to exacerbate the experience of physical and mental stress among immigrant women.

\section{Gender and age-related vulnerabilities}

Participants identified immigrant women and youth as being particularly vulnerable to the mental health impacts of the resettlement process. From their experience working with immigrant clients, immigrant women were more likely to have limited language skills, be disconnected from community life, and experience loneliness than their male counterparts. Coincidentally, more of their clients seeking help to deal with issues of depression and emotional problems were immigrant women. A focus group participant explained the gendered nature of mental health vulnerabilities among immigrant groups: 
The loss of social networks can be a huge factor for women, even more so than for men if they are not working. . You can at least forge some networks at work, right? If you don't have access to those networks because you are staying home-and again, language barriers come in there as well, sometimes social barriers too-especially the husband either enforces staying at home for the wife, for example. So yeah, I would say the women are far more at risk of loneliness. - [Focus group 3 participant].

Immigrant youth also struggled with gaining social acceptance from their non-immigrant peers. Our participants observed that youth from immigrant backgrounds tended to be excluded from play activities, and thus were more likely to face loneliness in school settings. According to participants, in their desperation to gain social acceptance, immigrant youths often turned to street communities, including those involved in illicit drug and gang activities. The consequences of such involvement were observed to include drug use and long-term mental health problems. A participant explained the relationship between social isolation and adverse social outcomes for immigrant youths:

For the teenagers it's. . wanting to fit in, being accepted by the marginalized Canadian kids, who are the kids who don't have stable homes, are on drugs, you know. They are the ones who will accept the immigrant kids first, and so that's what builds the view of the immigrant kids, what is normal in Canadian society, but it is not. And then they tell their parents all Canadian kids are allowed to go out till 2 o'clock. . I I certainly won't let my kid do that, but they have never seen a healthy Canadian family. - [Individual interview 03].

These narratives highlight the peculiar nature of mental health vulnerability among immigrant women and youth. More importantly, they also illustrate the role of race as a mental health determinant among immigrant groups, in particular the lack of social acceptance and isolation imposed by their minority status in Canada.

\section{Lack of appropriate mental health supports}

Despite the numerous mental health stressors confronting immigrants, the province was noted as having inadequate mental health supports for immigrant families. Culturally appropriate and clientcentered mental health supports were reportedly too few in mainstream service provision. Participants noted that the stigmatization of mental health conditions in the immigrant communities required that serious attention be paid to issues of privacy and confidentiality when immigrants present at healthcare facilities with mental illness. Our participants, however, observed a tendency among healthcare workers to handle the mental health issues of immigrants with some degree of levity, which served to discourage their utilization of available mental health supports. An interview participant explained:

If somebody with trauma...go to the emergency room because they have these terrible thoughts, what happens? They get put in a little room which has very questionable privacy because it might be just with the curtains around. And then somebody asks them very private questions...let's say it's a woman from a camp who was raped. And now she has memories coming. Is she going to say that? No, she is not...She might tell them what symptoms she has, and she is going to be diagnosed with schizophrenia because then it looks like she has hallucinations, while it is actually memories. So, she gets medication, which is not helping because she doesn't have schizophrenia, she has PTSD. So, after this experience, she is not going to go back, and she is going to tell her friends don't go there, [it] makes you worse...they get traumatized, re-traumatized in the process. - [Individual interview 04].

Our participants suggested that the lack of appropriate mental health supports, and treatments has resulted in several instances of misdiagnoses and mishandling of mental health conditions affecting immigrant groups in the province, which served to further disconnect immigrants from mainstream services.

\section{DISCUSSION}

In this study, we drew upon intersectionality theory to explore service providers' perspectives on the determinants of immigrants' mental health in Alberta, Canada. The identified determinants possess structural characteristics, and thus require structurallevel remedies. They also intersect to produce complex effects on the mental health and well-being of immigrant populations in Alberta. 
Notable among these intersecting determinants is the role of precarious immigration status, which typically invokes fear of deportation, impedes access to critical services, and creates uncertainties about life itself. Temporary foreign workers, undocumented migrants, and refugee claimants were particularly vulnerable to the mental health stress associated with precarious immigration status. This stress is understandable in light of existing Canadian immigration policies, which allow temporary foreign workers and refugee claimants only a limited period of stay in Canada (Jackson \& Bauder, 2013; Strauss \& McGrath, 2017). It is thus possible that these classes of immigrants feel anxious about returning to their home countries, possibly to the same socioeconomic or political conditions that triggered their emigration. Perhaps, it is the fear of returning to adverse economic and political conditions in their home countries that forces some temporary workers to remain in Canada as undocumented or illegal migrants, a status that limits their access to publicly funded healthcare resources, including mental health supports. The poor mental health status of temporary foreign workers, refugee claimants, and undocumented migrants can therefore be attributed to their low socioeconomic status, low wages, poor housing and working conditions, and poor access to essential services (Salami, Meharali, \& Salami, 2015). We further suggest that the social stratification of residents into temporary and permanent classes, with very different rights and privileges, invokes a sense of social inequality and a feeling of mental discomfort for those who feel disadvantaged, particularly temporary foreign workers and refugee claimants. In a recent study in Australia, Straiton et al. (2014) identified similar drivers of mental health disadvantages for immigrant populations with precarious status, especially when such liminality intersects with language barriers.

The deskilling of immigrants in the labour market also presents enormous challenges to their mental well-being. Immigrants in Alberta and across Canada demonstrate a disproportionate presence in those segments of the job market that offer minimum wages and require very little professional skills (George, Chaze, Fuller-Thompson, \& Brennenstuhl, 2012; Human Resources Development Canada, 2013; Islam, 2013; Robert \& Gilkinson, 2012). This quagmire exists despite widespread acknowledgement that immigrants are some of the most educated and professionally qualified groups in Canada. In addition to low wages, this form of labour force participation offers limited opportunities for job satisfaction, career progression, and socioeconomic mobility. Consequently, our participants noted widespread poverty, depression, and anxiety among immigrants who have experienced deskilling. Racism, limited social networks, and lack of recognition for foreignacquired educational and professional qualifications are some of the factors that contribute to the perpetual entrapment of immigrants in minimumwage jobs in Alberta and across Canada. This finding confirms earlier reports of deskilling and employment discrimination against immigrants in Canada (Buzdugan \& Halli, 2009; Creese \& Wiebe, 2012). In this paper, we have gone a step further to suggest possible connections between labour discriminatory practices and immigrants' mental health.

Although social supports and a sense of community belonging are critical resources for mental health, our participants reported a general feeling of social isolation among immigrants in Alberta. Previous research evidence also indicates that new comers with limited community attachment and social networks have a greater risk for poor mental health outcomes (Chadwick \& Collins, 2015; Puyat, 2013), possibly because the absence of such relationships can create significant gaps in the resettlement process (Tran et al., 2014). Other researchers in this area have suggested a correlation between lack of social supports and several mental health problems, including depression and emotional problems (Delara, 2016; Ornelas \& Perreira, 2011; Puyat, 2013).

Our findings also demonstrate the extent to which sociocultural stress affects the mental well-being of immigrants. Exposure to Western values and norms of behaviour, we noted, undergirds tensions and changing power relations in immigrant families. Although new patterns of power and gender relations might seem empowering to previously disenfranchised women and children, they encapsulate seeds of family conflict and disintegration. As our participants reported, the high prevalence of family violence, divorce, single parenthood, and parent-child conflicts among immigrants can be attributable to the sociocultural stress that they face as part of the resettlement process. Family disintegration, in turn, has proven to be detrimental to the mental well-being of 
immigrants (Donnelly et al., 2011; Durbin, Lin, Moineddin, Steel, \& Glazier, 2014; Hollander, Bruce, Burstrom, \& Ekblad, 2011; Pahwa, Karunanayake, McCrosky, \& Thorpe, 2012; Singhammer \& Bancila, 2011). Previous studies have indeed shown that family violence and parental stress put more immigrants than non-immigrants at risk for mental health problems (Browne et al., 2017; Lee \& Hadeed, 2009).

For a large number of immigrant women, economic pressures upon arrival often add a layer of mental health stress to the challenges posed by their traditional roles as mothers and homemakers. The physical and mental stress associated with balancing work and childcare has serious mental health implications for immigrant women, including depression and anxiety (Ornelas, Perreira, Beeber, \& Maxwell, 2009). We suggest that the mental health impact of post-migration socioeconomic pressures are particularly salient for immigrant women who lack informal support networks and who are embracing the work-family balance for the first time. There is thus a need for interventions to address family-work balance. Such interventions may range from financial assistance programs to counselling.

These mental health determinants often intersect to produce complex mental health problems for immigrants. For example, precarious immigration status, unemployment, and isolation often converge to create loneliness and depression among undocumented temporary foreign workers. Similarly, socioeconomic pressures (e.g., inadequate income) and sociocultural pressures (e.g., family conflicts) often also act simultaneously to increase anxiety and emotional stress for immigrant women. Despite the widespread nature of these mental health risks, Canada's mental health support system appears to be culturally unprepared to accommodate the mental health needs of most immigrants. The overall impact of these intersecting influences has been the erosion of the 'healthy immigrant effect' after a period of stay in Canada (Islam, 2013; Vang et al., 2015). We believe that the interaction of these determinants contributes to mental health degradation for immigrants in Alberta. This pattern of mental health decline has also been reported in Europe (Rivera et al., 2016), which thus calls for a global response to the multiplicity of mental health risks confronting immigrants.

\section{LIMITATIONS}

Although our study presents several insights on the determinants of immigrants' mental health, it also has some important limitations, including its narrow focus on a singular Canadian province. Research in the other Canadian provinces can thus help to produce a more nuanced understanding of the mental health vulnerabilities of immigrants in Canada. Our study was also based on interviews and focus groups conducted with service providers, whose views may differ from those held by immigrants with lived experiences of mental health problems. Also, our participants were themselves predominantly immigrants. As such, they may have, in some instances, conflated their own experiences with those of their clients. Future research should therefore consider integrating perspectives from immigrants themselves.

\section{CONCLUSION}

To conclude, our research has identified the key factors affecting the mental health of immigrants in Alberta. These factors are structural, macro-level mental health determinants that lie beyond the control of individual immigrants. Our findings thus support earlier suggestions to redirect discursive explanations of immigrants' health to focus more on structural-level influences. In this regard, we recommend the adoption of a social determinants of health framework for addressing the mental health vulnerabilities of immigrants. Such an approach might include adopting policy interventions, institutional practices, and support systems that address precarious immigration status, poverty, unemployment, service inaccessibility, and sociocultural stress among immigrants.

\section{REFERENCES}

Ali, J. (2002). Mental health of Canada's immigrants. Supplement to Health Reports, 2002(13), 111.

Braun, V., \& Clarke, V. (2006). Using thematic analysis in psychology. Qualitative Research in Psychology, 3(2), 77-101. doi: 10.1191/1478088706qp063oa

Browne, D. T., Kumar, A., Puente-Duran, S., Georgiades, K., Leckie, G., \& Jenkins, J. (2017). Emotional problems among recent 
immigrants and parenting status: Findings from a national longitudinal study of immigrants in Canada. PLoS One 12(4), e0175023. doi: org/10.1371/journal.pone.0175023.

Buzdugan, R., \& Halli, S. S. (2009). Labor market experiences of Canadian immigrants with focus on foreign education and experience. International Migration Review, 43(2), 366386. doi:10.1111/j.1747-7379.2009.00768.x

Chadwick, K. A., \& Collins, P. A. (2015). Examining the relationship between social support availability, urban center size, and selfperceived mental health of recent immigrants to Canada: A mixed-methods analysis. Social Science \& Medicine, 128, 220-230.

doi:

10.1016/j.socscimed.2015.01.036

Collins, P. H. (2000). Gender, black feminism, and black political economy. Annals of the American Academy of Political \& Social Science, 568(1), 41-53. doi:10.1177/000271620056800105

Creese, G., \& Wiebe, B. (2012). 'Survival employment': Gender and deskilling among African immigrants in Canada. International Migration, 50(5), 56-76. doi:10.1111/j.14682435.2009. 00531.x

Crenshaw, K. (1989). Demarginalizing the intersection of race and sex: A black feminist critique of antidiscrimination doctrine, feminist theory and antiracist politics. University of Chicago Legal Forum, 1989(1), Article 8.

Delara, M. (2016). Social determinants of immigrant women's mental health. Advances in Public Health, 2016. doi:10.1155/2016/9730162

Donnelly, T. T., Hwang, J. J., Este, D., Ewashen, C., Adair, C., \& Clinton, M. (2011). If I was going to kill myself, I wouldn't be calling you. I am asking for help: Challenges influencing immigrant and refugee women's mental health. Issues in Mental Health Nursing, 32(5), 279-290. doi:10.3109/01612840.2010.550383

Durbin, A., Lin, E., Moineddin, R., Steele, L. S., \& Glazier, R. H. (2014). Use of mental health care for nonpsychotic conditions by immigrants in different admission classes and by refugees in Ontario, Canada. Open Medicine, 8(4), e136-e146.

George, U., Chaze, F., Fuller-Thomson, E., \& Brennenstuhl, S. (2012). Underemployment and life satisfaction: A study of internationally trained engineers in Canada. Journal of Immigrants and Refugee Studies, 10(4), 407-425. doi:10.1080/15562948.2012.717827

Hollander, A., Bruce, D., Burstrom, B., \& Ekblad, S. (2011). Gender-related mental health differences between refugees and nonrefugee immigrants: A cross-sectional register-based study. BMC Public Health, 11(180). doi:10.1186/1471-2458-11-180

Human Resources Development Canada. (2013). Human Resources and Skills Development: Annual report, Canada 2013. Retrieved from http://www12.hrsdc.gc.ca

Islam, F. (2013). Examining the "healthy immigrant effect" for mental health in Canada. University of Toronto Medical Journal, 90(4), 169-175.

Islam, F., \& Oremus, M. (2014). Mixed methods immigrant mental health research in Canada: A systematic review. Journal of Immigrant \& Minority Health, 16, 12841289. doi:10.1007/s10903-013-9962-x

Jackson, S., \& Bauder, H. (2013). Neither temporary, nor permanent: The precarious employment experiences of refugee claimants in Canada. Journal of Refugee Studies, 27(3), 360-381. doi:10.1093/jrs/fet048

Kennedy, S., Kidd, M. P., McDonald, J. T., \& Biddle, N. (2015). The healthy immigrant effect: Patterns and evidence from four countries. International Migration \& Integration, 16, 317-332. doi:10.1007/s12134-014-0340-x

Kirmayer, L. J., Narasiah, L., Munoz, M., Rashid, M., Ryder, A. G., Guzder, J., . . . Pottie, K. (2011). Common mental health problems in immigrants and refugees: General approach in primary care. Canadian Medical Association Journal, 183(12), E959-E967. doi:10.1503/cmaj.090292

Lee, Y. S., \& Hadeed, L. (2009). Intimate partner violence among Asian immigrant communities: Health/mental health consequences, help-seeking behaviors, and service utilization. Trauma, Violence, \& Abuse, 10(2), 143-170. doi:10.1177/1524838009334130

Lincoln, Y. S., \& Guba, E. G. (1985). Naturalistic inquiry. Beverly Hills, CA: Sage.

Menezes, N. M., Georgiades, K., \& Boyle, M.H. (2011). The influence of immigrant status and 
concentration on psychiatric disorder in Canada: A multi-level analysis. Psychological Medicine, 41(10), 2221-2231. doi:10.1017/S0033291711000213

Nangia, P. (2013). Discrimination experienced by landed immigrants in Canada. RCIS Working Papers (Working paper no. 2013/7). Retrieved from http://www.ryerson.ca/content/dam/rcis/d ocuments/RCIS_WP_Parveen_Nangia_No_2 013_7.pdf

$\mathrm{Ng}$, E. (2011). The healthy immigrant effect and mortality rates. Health Reports, 22(4), 2529.

Ng, E., \& Omariba, W. R. (2010). Is there a healthy immigrant effect in mental health? Evidence from population-based health surveys in Canada. In J. Jedwab \& S. Kooi (Eds.), Canadian Issues: Immigrant Mental Health (pp. 23-28). Retrieved from http://www.metropolis.net/pdfs/immigrant _mental_health_10aug10.pdf

Ornelas, I. J., \& Perreira, K. M. (2011). The role of migration in the development of depressive symptoms among Latino immigrant parents in the USA. Social Science \& Medicine, 73(8), 1169-1177. doi: 10.1016/j.socscimed.2011.07.002

Ornelas, I. J., Perreira, K. M., Beeber, L., \& Maxwell, L. (2009). Challenges and strategies to maintaining emotional health: Qualitative perspectives of Mexican immigrant mothers. Journal of Family Issues, 30(11), 1556-1575. doi:10.1177/0192513X09336651

Pahwa, P., Karunanayake, P., McCrosky, J., \& Thorpe, L. (2012). Longitudinal trends in mental health among ethnic groups in Canada. Chronic Diseases and Injuries in Canada, 32(3), 164-176.

Puyat, J. H. (2013). Is the influence of social support on mental health the same for immigrants and non-immigrants? Journal of Immigrant \& Minority Health, 15(3), 598-605. doi:10.1007/s10903-012-9658-7

Rachel, B., Mladovsky, P., Ingleby, D., Mackenbach, J. P., \& McKee, M. (2013). Migration and health in an increasingly diverse Europe. Lancet, 381(9873), 1235-1245. doi:10.1016/S0140-6736(12)62086-8

Rivera, B., Casal, B., \& Currais, L. (2016). The healthy immigrant effect on mental health: Determinants and implications for mental health policy in Spain. Administration and Policy in Mental Health \& Mental Health Services Research, 43(4), 616-627. doi:10.1007/s10488-015-0668-3

Robert, A. M., \& Gilkinson, T. (2012). Mental health and well-being of recent immigrants in Canada: Evidence from the Longitudinal Survey of Immigrants to Canada (LSIC). Retrieved from http://www.cic.gc.ca/english/resources/res earch/mental-health.asp

Salami, B., Meharali, S., \& Salami, A. (2015). The health of temporary foreign workers in Canada: A scoping review.

Salami, B., Salma, J., \& Hegadoren, K. (2019). Access and utilization of mental health services for immigrants and refugees: Perspectives of immigrant service providers. International Journal of Mental Health Nursing, 28(1), 152161.

Sandelowski, M. (2000). Whatever happened to qualitative description? Research in Nursing \& Health, 23(4), 334-340. doi:10.1002/1098-240X.

Shishehgar, S., Gholizadeh, L., DiGiacomo, M., \& Davidson, P. M. (2015). The impact of migration on the health status of Iranians: An integrative literature review. BMC International Health Human Rights, 15(20), 1-11. doi:10.1186/s12914-015-0058-7

Singhammer, J., \& Bancila, D. (2011). Associations between stressful events and self-reported mental health problems among nonWestern immigrants in Denmark. Journal of Immigration \& Minority Health, 13(2), 371788. doi:10.1007/s10903-009-9281-4

Srirangson, A., Thavorn, K., Moon, M., \& Noh, S. (2013). Mental health problems in Thai immigrants in Toronto, Canada. International Journal of Culture \& Mental Health, 6, 156-169. doi:10.1080/17542863.2012.677459

Stafford, M., Newbold, B. K., \& Ross, N. A. (2011). Psychological distress among immigrants and visible minorities in Canada: A contextual analysis. International Journal of Social Psychiatry, 57(4), 428-441. doi:10.1177/0020764010365407

Statistics Canada (2018). Immigration and Ethnocultural Diversity Highlight Tables, 2016 Census. Retrieved from https://www12.statcan.gc.ca/census- 
recensement/2016/dp-pd/hlt-

$\mathrm{fst} / \mathrm{imm} /$ index-eng.cfm

Statistics Canada (2013). Immigration and ethnocultural diversity in Canada, National Household Survey, 2011 (Catalogue no. 99010-X2011001). Retrieved from https://www12.statcan.gc.ca/nhsenm/2011/as-sa/99-010-x/99-010x2011001-eng.cfm

Statistics Canada (2016). Immigration and ethnocultural diversity: Key results from the 2016 Census. Retrieved from https://www12.statcan.gc.ca/censusrecensement/2016/rt-td/imm-eng.cfm

Straiton, M., Grant, J. F., Winefield, H. R., \& Taylor, A. (2014). Mental health in immigrant men and women in Australia: The Northwest Adelaide Health Study. BMC Public Health, 14(1111), 1-15. doi:10.1186/1471-2458-14-1111

Strauss, K., \& McGrath, S. (2017). Temporary migration, precarious employment and unfree labour relations: Exploring the 'continuum of exploitation' in Canada's Temporary Foreign Worker Program. Geoforum, 78, 199-208. doi:10.1016/j.geoforum.2016.01.008

Tran, A. N., Ornelas, I. J., Kim, M., Perez, G., Green, M., Lyn, M. J., \& Corbie-Smith, G. (2014). Results from a pilot promotora program to reduce depression and stress among immigrant Latinas. Health Promotion Practice, 15(3), 365-372. doi:10.1177/1524839913511635

United Nations Department of Economic and Social Affairs, Population Division (2020). International Migration 2020. Retrieved from

https://reliefweb.int/sites/reliefweb.int/file s/resources/International\%20Migration\%20 2020\%20Highlights.pdfVang, Z., Sigouin, J., Flenon, A., \& Gagnon, A. (2015). The healthy immigrant effect in Canada: A systematic review. Population Change and Life Course Strategic Knowledge Cluster Discussion Paper Series, 3(1). Retrieved from http://ir.lib.uwo.ca/pclc/vol3/iss1/4

Viruell-Fuentes, E. A., Miranda, P. Y., \& Abdulrahim, S. (2012). More than culture: Structural racism, intersectionality theory, and immigrant health. Social Science \& Medicine, 75(12), 2099-2106. doi:10.1016/j.socscimed.2011.12.037

Weis, L., \& Fine, M. (2000). Speed bumps: A student friendly guide to qualitative research. New York, NY: Teachers College Press. 